\author{
Eva Teshajev Sunderland \\ ORCID: 0000-0003-2202-548X \\ Adam-Mickiewicz-Universität Poznań, Poznań \\ Europa-Universität Viadrina, Frankfurt (Oder)
}

DOI: $10.19195 / 0435-5865.143 .26$

\title{
Bezug zur Zeitgeschichte in Wörterbüchern. Die Widerspiegelung der deutsch-polnischen Beziehungen im Stownik języka polskiego (1958-1969), herausgegeben von Witold Doroszewski, vor dem Hintergrund des Zweiten Weltkriegs und der Nachkriegspolitik
}

\begin{abstract}
s
Ausgehend von der Tatsache, dass Sprachwörterbücher ebenfalls einen Einblick in die Zeitgeschichte und somit in politische, gesellschaftliche und kulturelle Aspekte geben, werden im vorliegenden Beitrag die zur Veranschaulichung der Stichwörter verwendeten Belegbeispiele aus ausgewählten Lemmastrecken (A, B, C, Ć, K, Z, Ź und Ż) des einsprachigen polnischen Wörterbuchs Stownik języka polskiego (1958-1969) daraufhin untersucht, welches Bild sie von den Deutschen und den deutsch-polnischen Beziehungen in der Nachkriegszeit transportieren. Dabei konnte festgestellt werden, dass das Thema Deutschland zwar nur selten im Wörterbuchs auftaucht, die vorhandenen Belegbeispiele mit Deutschenbezug jedoch ein negatives Deutschenbild, das tatsächlich im Nachkriegspolen präsent war, vermitteln.
\end{abstract}

Schlüsselwörter: Wörterbuchschreibung, deutsch-polnische Beziehungen, Zeitgeschichte 


\section{References to recent history in dictionaries. How German-Polish relations are reflected in the Stownik języka polskiego (1958-1969), edited by Witold Doroszewski, with regard to World War II and post-war politics}

Dictionaries can give us an insight into the history of a certain period and its political, social and cultural aspects. Therefore, this article has explored the image of the Germans and German-Polish relations in post-war times found in the monolingual Polish dictionary Słownik języka polskiego (1958-1969). The author conducted this analysis by reviewing all the headwords listed under certain letters (A, B, C, Ć, K, Z, Ź and Ż) in this dictionary, then examining the example sentences she found which mentioned these topics. Results show that although the topic of Germany occurs rarely in the dictionary, the example sentences that do contain references to the Germans reveal a negative image which corresponds to the widespread Polish image of the Germans in post-war times.

Keywords: lexicography, German-Polish relations, recent history

Eva Teshajev Sunderland, Uniwersytet im. Adama Mickiewicza, Instytut Lingwistyki Stosowanej, Al. Niepodległości 4, 61-874 Poznań, Polen, E-Mail: etesha@amu.edu.pl

Received: 30.09.2017, accepted: 18.05.2018

\section{Einführung}

Über ihre Funktion als Quellen sprachlicher Informationen hinaus sind Sprachwörterbücher immer auch ein Spiegel der Epoche, in der sie entstanden sind, da sich aus den Bedeutungsangaben der verzeichneten Stichwörter und aus den im Stichwortartikel enthaltenen Belegbeispielen bzw. Beispielsätzen Schlüsse über politische, soziale und kulturelle Aspekte der Epoche ziehen lassen. Insbesondere die zur Veranschaulichung des Stichwortes angeführten Belegbeispiele, die während der Exzerptionsarbeiten aus der zeitgenössischen Presse, schönen Literatur, aber auch Fachliteratur entnommen wurden, geben einen Einblick in die außersprachliche Situation während der Entstehungszeit des Wörterbuchs. Daher lohnt es sich stets Wörterbücher nicht nur aus der linguistischen, sondern auch aus der kulturhistorischen Perspektive zu untersuchen.

Wie sich der entsprechende zeitgeschichtliche Bezug in bestimmten Bereichen äußert, soll anhand eines der wichtigsten Wörterbücher der polnischen Sprache des 20. Jahrhunderts dargestellt werden - des „Słownik języka polskiego", herausgegeben von Witold Doroszewski (im Folgenden SJPDor abgekürzt). Im Mittelpunkt steht dabei die Frage, welche Informationen die Belegbeispiele im SJPDor über das im Nachkriegspolen verbreitete Deutschenbild in Anbetracht der Erfahrungen des Zweiten Weltkriegs und der Entwicklungen nach 1945 liefern. 


\section{Das Stownik języka polskiego (1958-1969), herausgegeben von Witold Doroszewski - eine Kurzdarstellung}

Das SJPDor besteht aus 10 Bänden und einem Ergänzungsband, die zwischen 1958 und 1969 herausgegeben wurden. Es enthält pro Teilbedeutung eines Stichwortes bzw. Lemmas bis zu sechs Belegbeispiele, was im Vergleich zu anderen polnischen Wörterbüchern eine sehr hohe Anzahl ist. Diese Belegbeispiele sind einer sehr umfangreichen Quellenbasis mit insgesamt 3600 Positionen entnommen worden, da die dem Wörterbuch zugrunde liegenden Texte aus der Zeit von der zweiten Hälfte des 18. Jahrhunderts bis in die 1960er Jahre stammen, wobei allerdings bei der Wahl von Beispielsätzen nur selten auf Quellen aus dem 18. Jahrhundert zurückgegriffen wurde (Bartnicka 2000: 18). Somit geben die entsprechenden Belegbeispiele sozusagen einen Einblick in die Geschichte Polens von der Teilungszeit bis zur Volksrepublik. Auch wenn das SJPDor zwar nicht primär ein Bild der Volksrepublik liefert, da viele der Beispielsätze aus Quellen des 19. Jahrhunderts stammen, so ist dennoch die Gegenwart Volkspolens in hohem Maße im Wörterbuch präsent.

Die Vorbereitungsarbeiten für das SJPDor begannen im Jahre 1950, in einer Zeit, die nicht nur in Polen, sondern weltweit von einem gravierenden Wandel geprägt war. In der Volksrepublik brachte das neue politische System tiefgreifende Veränderungen mit sich, die sich auf alle Lebensbereiche auswirkten. Diese Veränderungen wurden durch die Auswahl von Belegbeispielen aus entsprechenden Quellen auch im SJPDor widergespiegelt. Zu den Themen, die somit Eingang in die Stichwortartikel des SJPDor fanden, gehören die Entwicklung des Sozialismus und die Rolle der Polnischen Vereinigten Arbeiterpartei PZPR im neuen Gesellschaftssystem, ${ }^{1}$ das propagandistische negative Bild von der (katholischen) Kirche ${ }^{2}$ die positive Darstellung des Verhältnisses zwischen Polen und der So-

${ }^{1}$ So findet sich unter dem Stichwort zacieśniać (im übertragenen Sinne: enger schnüren, festigen) der folgende Satz:

Polska Zjednoczona Partia Robotnicza umacnia nieustannie sojusz robotniczo-chtopski [...] zacieśnia spójnię między miastem a wsią. Stat. PZPR 9. (Statut Polskiej Zjednoczonej Partii Robotniczej uchwalony przez II Zjazd PZPR. Warszawa 1955.)

(,,Die Polnische Vereinigte Arbeiterpartei festigt beständig das Arbeiter-Bauern-Bündnis [...] sie festigt das einigende Band zwischen Stadt und Land.")

${ }^{2}$ Zum Beispiel im Stichwortartikel burżua (Bourgeois): Cyniczny i załgany, brutalny i tchórzliwy burżua nie zapomina, że w religii, która osobiście pogardza, może znaleźć sojusznika w walce z postępem. Twórcz. 4, 1951, s. 112. (Twórczość. Nr. 4. Miesięcznik Związku Literatów Polskich. Czytelnik: Warszawa 1951.)

(„Der zynische und verlogene, brutale und feige Bourgeois vergisst nicht, dass er in der Religion, die er persönlich verachtet, einen Verbündeten im Kampf gegen den Fortschritt finden kann.“) 
wjetunion, ${ }^{3}$ das neue Verständnis von der Rolle der Kunst, ${ }^{4}$ die Kollektivierungsmaßnahmen auf dem Lande ${ }^{5}$ und die Jahrespläne in der Wirtschaft. ${ }^{6}$ Des Weiteren erfährt man aus dem SJPDor etwas über die aktuellen internationalen politischen Ereignisse der Zeit und den Kalten Krieg. ${ }^{7}$

Darüber hinaus offenbart sich im Wörterbuch aber auch das damalige Verhältnis Polens zu den Deutschen, das aufgrund der Kriegsgeschehnisse und der schwierigen politischen Beziehungen nach dem Krieg (vor allem wegen der fehlenden Anerkennung der Oder-Neiße-Grenze durch die BRD) eine hohe Relevanz aufwies und sowohl für die Gegenwart als auch für die Zukunft Polens wesentlich war.

${ }^{3}$ Unter dem Lemma anulować (annulieren):

W rezultacie konsekwentnego realizowania prawa narodów do samookreślenia młoda Republika Radziecka anulowała grabież ziem polskich przez carat i przyznała Polsce niepodległość. Nowe Drogi 2, 1951, s. 109. (Nowe Drogi. Nr. 2. Miesięcznik. Organ teoretyczny i polityczny Komitetu Centralnego Polskiej Zjednoczonej Partii Robotniczej. Warszawa 1951.)

(,,Als Ergebnis einer konsequenten Verwirklichung des Selbstbestimmungsrechts der Völker anullierte die junge Sowjetunion den Raub der polnischen Gebiete durch das Zarenreich und erkannte Polens Unabhängigkeit an. ")

${ }^{4}$ Im Stichwortartikel zaangażować (engagieren):

Krytyk - jako twórca - musi być aktywista walki o jutro, o nową sztukę, o nowa kulturę, musi się $w$ tej walce zaangażować bez reszty. Twórcz. 6, 1953, s. 180. (Twórczość. Nr. 6. Miesięcznik Związu Literatów Polskich. Czytelnik: Warszawa 1953.)

(,,Der Kritiker muss - in der Rolle des Schöpfers - ein Aktivist im Kampf um eine neue Zukunft, eine neue Kultur sein; er muss sich in diesem Kampf restlos engagieren.")

${ }^{5}$ Unter dem Stichwort zespolowy (Gruppen-):

Członkowie spółdzielni, którzy szczerze wzięli się do pracy na zespołowej gospodarce, już dzisiaj żyja dostatniej, niż żyli na gospodarstwie indywidualnym. Głos Wielkopol. 268, 1954. (Gtos Wielkopolski. Nr. 268. Dziennik. Czytelnik: Poznań 1954.)

(,,Jene Mitglieder der [landwirtschaftlichen] Produktionsgenossenschaft, die mit aufrichtigem Engagement im gemeinsamen landwirtschaftlichen Betrieb mitgearbeitet haben, leben bereits heute in größerem Wohlstand als früher, als sie noch auf ihrem Einzelhof wohnten. ")

${ }^{6}$ Über den 3-Jahresplan gibt ein Beleg unter dem Lemma zdewastować (zerstören) Auskunft:

Plan trzyletni jako główne zadanie stawiał odbudowę istniejących, ale zdewastowanych i zniszczonych w czasie wojny zakładów. Nowe Drogi 6, 1952, s. 20. (Nowe Drogi. Nr. 6. Miesięcznik. Organ teoretyczny i polityczny Komitetu Centralnego Polskiej Zjednoczonej Partii Robotniczej. Warszawa 1952.)

(,Die Hauptaufgabe des 3-Jahresplans bestand in einem Wiederaufbau der bestehenden, aber während des Krieges beschädigten oder zerstörten Betriebe. ")

${ }^{7}$ So unter burzyć in seiner übertragenen 4. Bedeutung (przen. a) «być poruszonym wewnętrznie, podnieconym pod wpływem gwałtownych uczuć» - innerlich erschüttern):

Burzy się we mnie wszystko na myśl, że sa na świecie ludzie-imperialiści, którzy chca ponownie rozpętać straszną rzeź wojenna, niosaca śmierć i pożogę. Pokój 61. (Bielicki, Marian / Lau, Jerzy [Hrsg.]: O pokój. Wiersze poetów polskich. Wydawnictwo Prasa Wojskowa: Warszawa 1950.)

(, Es brodelt in mir beim Gedanken, dass es auf dieser Welt Menschen, Imperialisten, gibt, die wieder ein schreckliches Kriegsmassaker hervorrufen wollen, das Tod und verbrannte Erde hinterlassen wird.")

Germanica Wratislaviensia 143, 2018

(C) for this edition by CNS 
Wie sich diese Haltung und das Deutschenbild in den Belegbeispielen im SJPDor niederschlägt, soll im Folgenden näher beschrieben werden. Zunächst folgt jedoch ein kurzer Überblick über die Entstehung des polnischen Deutschenbildes im Laufe der Geschichte.

\section{Das polnische Deutschenbild - historische Hintergründe}

Obwohl die deutsch-polnische Nachbarschaft angesichts des Akts von Gnesen im Jahre 1000 auf einen ,konstruktiven Anfang“ (Vgl. Zernack 2001: 94) zurückblicken kann, wurden die deutsch-polnischen Beziehungen zunächst durch den Konflikt zwischen dem Deutschen Orden und dem Königreich Polen gestört und verschlechterten sich langfristig aufgrund der Teilungen Polens durch Preußen, Russland und Österreich. Zwar stellten Vormärz und Völkerfrühling und die damit verbundene Polenbegeisterung in Süddeutschland einen Lichtblick in den deutsch-polnischen Beziehungen dar, doch angesichts der Dominanz Preußens über die deutschen Kleinstaaten währte diese Phase der Polenfreundschaft nicht lange. Im preußischen Teilungsgebiet hingegen sorgten die antipolnische Politik Bismarcks, der Kulturkampf und die Germanisierung für einen Tiefpunkt im preuBisch-polnischen Verhältnis, der letztlich auch zu einer allgemeinen Verschlechterung der deutsch-polnischen Beziehungen führte, da nach der Gründung des Deutschen Reiches unter der Führung Preußens das negative Preußenbild allgemein auf die anderen Deutschen übertragen wurde. Nach dem Ersten Weltkrieg, in dessen Verlauf Polen seine Unabhängigkeit wiedergewann, bestand das negative Deutschenbild weiterhin fort, so dass Wrzesiński (1994: 72) zufolge für viele Polen die Machtergreifung Hitlers letztendlich nicht überraschend kam. Während aber in der Zwischenkriegszeit auf polnischer Seite noch zwischen Vertretern des deutschen Idealismus und Humanismus und den Anhängern des preußischen Pangermanismus unterschieden wurde, führten die Erfahrungen des Zweiten Weltkriegs zu einer Vereinheitlichung des Deutschenbildes und einer Gleichsetzung der Deutschen mit den Nationalsozialisten. Dies kam in einem Aufruf (vom 10. Januar 1942) der Repräsentanten der Polnischen Arbeiterpartei (Polska Partia Robotnicza, PPR), aus der später die Polnische Vereinigte Arbeiterpartei PZPR hervorgehen sollte, zum Ausdruck, in dem in Bezug auf die Deutschen vom ,ewigen Feind" gesprochen wird (Kiwerska 1993: 46-47). Nach Kriegsende und der damit einhergehenden Westverschiebung Polens gab es auf polnischer Seite Befürchtungen hinsichtlich eines erneuten Krieges ${ }^{8}$ und einer Grenzkorrektur, da westdeutsche Kreise die neue polnische Westgrenze infrage stellten. Neben den Erinnerungen an den Krieg und die deutsche Besatzung rief nun der Gedanke an

${ }^{8}$ Die Angst der polnischen Bevölkerung vor einem Kriegsausbruch wird unter anderem anschaulich in den berühmten Tagebüchern der polnischen Schriftstellerin Maria Dąbrowska (2009, Bd. VI: 32) beschrieben. 
deutsche Revisionsforderungen neue Ängste innerhalb der polnischen Bevölkerung hervor. Westdeutsche Remilitarisierungspläne in den 50er Jahren und entsprechende Äußerungen führender BRD-Politiker verstärkten die Furcht vor einem Verlust der ,wiedergewonnenen“ Gebiete im Westen noch zusätzlich. Gleichzeitig waren die Angst vor Revisionsforderungen und der Hass auf die Deutschen gerade in den ersten Jahren der Volksrepublik ein einigendes Element, das die Polen unabhängig von ihrer politischen Orientierung verband. Auch die Tatsache, dass die DDR im Jahre 1950 die Oder-Neiße-Grenze anerkannte, verbesserte das allgemeine Deutschenbild nicht. Zwar wurde in der offiziellen polnischen Presse im Rahmen der von oben verordneten „Völkerfreundschaft unter den sozialistischen Bruderstaaten“" zwischen der „kapitalistischen und feindlichen“ BRD und der DDR unterschieden und ein positives Bild der DDR aufgebaut, doch dieses künstliche Bild entsprach nicht den Ansichten der Bevölkerung und konnte sich daher nicht halten (Wrzesiński 1994: 74).

$\mathrm{Zu}$ einer Normalisierung des deutsch-polnischen Verhältnisses kam es erst in den 70er Jahren, wobei sich die Beziehungen zwischen Polen und der BRD vor allem in den 80er Jahren verbesserten, als viele Westdeutsche sich an der Pakethilfe für Polen beteiligten, so dass sogar bei einer Umfrage im Jahre 1989 die meisten befragten Polen (neben den USA und Japan) die BRD als eines der Länder, die ihnen am sympathischsten seien, angaben (Sakson 1993: 419).

\section{Die Widerspiegelung des Deutschenbildes und der deutsch-polnischen Beziehungen der Nachkriegszeit im SJPDor}

Die vorliegende Untersuchung des Deutschenbildes im SJPDor basiert auf einer Analyse der Lemmastrecken A, B, C, Ć (1. Band, 1958), K (3. Band, 1961), Z, Ź und $\dot{Z}$ (10. Band, 1968), sowie der entsprechenden Lemmastrecken A, B, C, Ć, K, Z, Ź und $\dot{Z}$ aus dem Ergänzungsband (11. Band, 1969).

Dabei konnte festgestellt werden, dass das polnische Deutschenbild, das sich anhand der zuvor skizzierten geschichtlichen Ereignisse und Erfahrungen über die Jahrhunderte hinweg formte, anhand von Belegbeispielen aus Werken der Belletristik, Fachliteratur und der Presse, die im Zeitraum vom Beginn des 19. Jahrhunderts bis in die 1950er Jahre entstanden sind, Eingang in das SJPDor fand.

Eine Auswertung aller gefundenen Beispielsätze, die das polnische Deutschenbild zum Inhalt haben, zeigt, dass bereits die frühe Geschichte der deutsch-polnischen bzw. deutsch-slawischen Beziehungen im SJPDor erwähnt wird. So wird unter dem Stichwort zaciążyć (beeinflussen) in einem Belegbeispiel aus einem Werk des Historikers Kazimierz Piwarski (1947) auf die negativen Folgen des deutschen „Drangs nach Osten“ für das gesamte Slawentum hingewiesen: 


\section{zacią̇yć (beeinflussen)}

$W$ wieku X dwa fakty zaciażyly złowrogo na dalszych dziejach Stowiańszczyzny. Pierwszy to zniszczenie przez Mongolskich Madziarów państwa wielkomorawskiego [...] Drugi fakt, to niemiecki „Drang nach Osten“ [parcie na wschód]. PIW. Odra 117. (Piwarski, Kazimierz: Odra rzeka pokoju. Towarzystwo Uniwersytetu Robotniczego: Warszawa 1947.) ${ }^{9}$

Piwarskis Werk „Odra rzeka pokoju“, demzufolge die Oder in Zukunft ein Fluss des Friedens sein soll, stand im Einklang mit der Idee der PZPR eine ,slawische Bastion gegen die Deutschen“" unter der Führung der Sowjetunion zu errichten (Kiwerska 1993: 48).

Daneben finden sich andere Belegbeispiele, die das deutsch-polnische Verhältnis im Mittelalter thematisieren, ${ }^{10}$ sowie Belegbeispiele, die sich auf den Konflikt mit dem Deutschen Orden ${ }^{11}$ und das Bild der Teilungsmacht Preußen ${ }^{12}$ beziehen.

Die Mehrzahl der in den Lemmastrecken enthaltenen Belegbeispiele, in denen Bezug auf Deutsche genommen wird, stehen jedoch mit dem Zweiten Weltkrieg in Zusammenhang, was mitunter darin begründet liegt, dass der Krieg und die Besatzungszeit ein Thema waren, das wiederholt in der Prosa, der Presse und den Geschichtsbüchern der Nachkriegszeit aufgegriffen wurde. Die Exzerption dieser Werke führte dazu, dass ihre Inhalte in das SJPDor einflossen. Zur Veranschaulichung vieler Stichwörter aus den Wortfeldern „Krieg“ und „Gewalt“ wurden somit Belegbeispiele verwendet, in denen deutsche Gewalt während des Zweiten Weltkriegs bzw. die deutschen Kriegsbestrebungen thematisiert werden. Sätze dieser Art finden sich unter den Stichwörtern anektować (annektieren), bat (Peitsche), barbarzyństwo (Barbarei), bić (schlagen), bijatyka (Schlägerei),

9 „Im 10. Jahrhundert hatten zwei Tatsachen einen unheilvollen Einfluss auf den Verlauf der Geschichte der Slawen. Erstens die Zerstörung des Großmährischen Reiches durch die Mongolischen Magyaren [...]. Zweitens der deutsche 'Drang nach Osten'.“

${ }^{10}$ żamać (brechen, zerschlagen)

Niemieccy mieszczanie krakowscy [...] podnieśli bunt przeciwko Łokietkowi. Łokietek złomat krwawo ich zuchwatstwo. SZAJN. Szkice 1, 131. (Szajnocha, Karol: Szkice historyczne. Bd. 1. K. Wild: Lwów 1858.) (,,Die deutschen Bürger Krakaus [...] erhoben sich gegen Władysław Ellenlang. Władysław Ellenlang bestrafte ihre Dreistigkeit blutig. ")

\section{1 zdradliwy (verräterisch)}

Znaleziono w papierach Świdrygietly niezaprzeczone dowody zdradliwych knowań Zakonu przeciw królowi i koronie polskiej. DZIED. Oleśn. I, 382. (Dzieduszycki, Maurycy: Zbigniew Oleśnicki. Bd. 1. Księgarnia i Wydawnictwo Dziet Katolickich i Naukowych: Kraków 1853.)

(,,In den Dokumenten des Swidrigiello wurden unbestreitbare Beweise für die Intrigen des Deutschen Ordens gegen den polnischen König und das Königreich gefunden. ")

\section{2 bezsumiennie (gewissenlos)}

Rząd pruski oddat [archiwa] na pastwe Niemcom przez siebie sprowadzonym i urzędnikom niemieckim, którzy wzgardzając społeczeństwem polskim, bezwzględnie i bezsumiennie je zatracili. KĘTRZ. Ludn. s. XIV. (Kętrzyński, Wojciech: O ludności polskiej w Prusiech niegdyś krzyżackich. Zakład Narodowy im. Ossolińskich: Lwów 1882.) (,,Die preußische Regierung hat [die Archive] den Deutschen, den ins Land geholten deutschen Beamten, zum Fraß vorgeworfen; diese verachteten die polnische Gesellschaft und ließen die Archive skrupellos und gewissenlos verfallen.") 
bojowiec (Kämpfer), bronić (verteidigen), bunkier (Bunker), gwalt (Gewalttat), kapitulacja (Kapitulation), kapitulant (Kapitulierender), kapitulować (kapitulieren), katiusza (Katjuscha-Rakete), katować (foltern), katownia (Folterkammer), kazamata (Kasematte), kocioł (milit. Kessel), kolejówka (die Zerstörung von Zügen durch Partisanen), komendant (Kommandant), kontyngentowy (Kontingent-), krwawy (blutig), zabić (töten), zaminować (Minen auslegen), zbrodniarz (Verbrecher), zbrodniczy (verbrecherisch), zbrodniczość (das Begehen von Verbrechen), zbrojenie (Rüstung), zbrojeniowy (Rüstungs-), zbrojownia (Waffenkammer), zbrojnie (bewaffnet), zniszczyć (zerstören), zwalczać (bekämpfen), zwasalizować (zu Vasallen machen) und żołdak (Söldner).

So wird z.B. unter dem Stichwort krwawy (in der Bedeutung 1. «zawierający krew, zmieszany z krwią; broczący, ociekający krwią, krwawiący; zbroczony krwią, zakrwawiony» - blutig) ein Belegbeispiel angeführt, dass von den Folterungen durch die Gestapo handelt:

\section{krwawy (blutig)}

1. «zawierajacy krew, zmieszany z krwia; broczacy, ociekajacy krwia, krwawiacy; zbroczony krwia, zakrwawiony»

Wiele dni trwały badania Gestapo. Oznaczały one pięść i obcas hitlerowskich zbirów, tortury, które zamieniaja ciało w krwawe strzępy. Ludzie KPP 18. (Ludzie KPP. Wydziat Historii Partii. Komitet Centralny Polskiej Zjednoczonej Partii Robotniczej. Ksiązka i Wiedza: Warszawa 1954. ${ }^{13}$

In einem Belegbeispiel im Stichwortartikel zabić (töten) wird wiederum eine Razzia im Ghetto geschildert:

\section{zabić (töten)}

Niemieckie samochody policyjne wjechaty za mury getta, umundurowani hitlerowcy wpadali do domów, zabijając ludzi na miejscu. LAMPE O nowa 208. (Lampe, Alfred: O nowa Polskę. Artykuly i przemówienia. Książka i Wiedza: Warszawa 1954. $)^{14}$

Aber auch abgesehen von den Wortfeldern „Krieg“ und „Gewalt“, werden Belegbeispiele, in denen Deutsche mit Gewalt in Verbindung gebracht werden, ebenfalls unter anderen Stichwörtern mit negativer Konnotation aufgeführt, so unter antysemityzm (Antisemitismus), bezprawność (Rechtlosigkeit), bezprawny (rechtlos), bobrować (Bedeutung 2. «przeszukiwać, szperać, grzebać, przewracać, plądrować» - durchsuchen, plündern), brunatny (przen. «hitlerowski» - braun im übertragenen Sinne), butnie (hochmütig), bydlak (przen. «obełżywie o człowieku małowartościowym moralnie, bezmyślnym, godnym pogardy» - Unmensch), $k a-$ torżniczy (Zwangsarbeits-), kloaczny (Jauchegruben-), nacjonalista (Nationalist), zaborczość (Machtgier), zachłanny (gierig), zaułkowość (Engstirnigkeit), zbydlęcenie (Degeneration), zdegenerować (degenerieren), żerować (einen Vorteil aus etwas herausschlagen).

13 „Die Verhöre der Gestapo dauerten viele Tage. Sie gingen einher mit Faustschlägen und Stiefeltritten der faschistischen Verbrecher, mit Folterungen, die den Körper in blutige Fetzen verwandeln.“

14 „Die deutschen Polizeiwagen fuhren in das Ghetto, uniformierte Faschisten stürmten die Häuser und töteten die Menschen an Ort und Stelle.“

Germanica Wratislaviensia 143, 2018

(C) for this edition by CNS 
Im Stichwortartikel butnie (hochmütig) ist z.B. von den hochmütigen deutschen Reaktionären, die den Anschluss Danzigs an das Reich vorbereiteten, die Rede:

\section{butnie (hochmütig)}

Reakcja niemiecka coraz butniej podnosiła głowę w Gdańsku, przygotowując stopniowe przytaczenie tego miasta do Rzeszy. BARB. Nauka 57. (Barbag, J. et al.: Nauka o Polsce i świecie współczesnym. Ksiązka do użytku szkolnego. 2. Aufl. Państwowe Zakłady Wydawnictw Szkolnych: Warszawa 1950. $)^{15}$

Im Belegbeispiel unter dem Stichwort zbydlęcenie (Degeneration) heißt es wiederum, dass während der Hitlerzeit das geistige Leben der Deutschen vollkommen degenerierte:

\section{zbydlęcenie (Degeneration)}

Epoka hitlerowska obniżła poziom ich [Niemców] życia duchowego, doprowadziła do zupetnego zbydlęcenia. DZIKOWSKI w: BYSTR. Warsz. 277. (Bystroń, Jan Stanisław: Warszawa. Zakończenie dopisał Stanisław Dzikowski (s. 267-285). J. Kubicki: Warszawa 1949.) ${ }^{16}$

Allerdings wurde auch eine hohe Anzahl von Belegbeispielen, die sich auf den Zweiten Weltkrieg beziehen und somit ein negatives Deutschenbild beinhalten, ebenfalls zur Veranschaulichung von Stichwörtern verwendet, die nicht negativ konnotiert sind. Dazu gehören die Stichwörter aptekarzewicz (Apothekerssohn), baczność (Wachsamkeit), bajka (Märchen), bezwarunkowy (bedingungslos), biologiczny (biologisch), bluffować (bluffen), brać (nehmen), but (Schuh), bydlęcy (Vieh-), byk (Stier), cacy (ei ei!), capnać (nach jemandem schnappen), cudzoziemski (ausländisch), kapitalny (großartig), kaput (Schluss und aus), karabinier (Carabiniere), kark (Nacken), kierownictwo (Führung, Leitung), koniecznie (unbedingt), konsekwentny (konsequent), krępacja (Verlegenheit), krótkowzroczność (Kurzsichtigkeit), robota (Arbeit), zarzucać (bewerfen), zaserwować (servieren, im übertragenen Sinne), zbiec (fliehen), zginać (verunglücken), zdeponować (deponieren), zewidencjować (Daten sammeln), zmechanizować się (sich der Funktionsweise eines Mechanismus angleichen), zmotoryzować (motorisieren), zostać (bleiben), zwężenie (Verengung), zwrotny (Wende-), żandarmski (Gendarmen-).

So finden sich z.B. unter dem Stichwort biologiczny (biologisch) Informationen über die geplante biologische Vernichtung durch die Nationalsozialisten:

\section{biologiczny (biologisch)}

Systematyczna akcja najeźdźców hitlerowskich, zmierzająca do biologicznego wyniszczenia narodu, szczególnie ostro dotknęła naukę polską. Zdrowie Publ. 5-6, 1948, s. 74. (Zdrowie publiczne. Nr. 5-6. Państwowe Zakłady Wydawnictw Lekarskich: Warszawa 1949. ${ }^{17}$

15 „Die deutschen Reaktionäre in Gdańsk wurden immer hochmütiger und bereiteten den allmählichen Anschluss dieser Stadt an das Dritte Reich vor.“"

16 „Die Hitlerzeit senkte das Niveau ihres [der Deutschen] geistigen Lebens und führte zu einer völligen Degeneration.“

17 „Die systematische Aktion der faschistischen Besatzer, die eine biologische Vernichtung des Volkes zum Ziel hatte, berührte in besonders starkem Maße die polnische Wissenschaft.“ 
Im Stichwortartikel koniecznie (unbedingt) ist wiederum ein Belegbeispiel aus einer kurz nach dem Krieg erschienenen Erzählung für Jugendliche angeführt, in dem es heißt, dass „die Deutschen unbedingt den Krieg wollen“:

\section{koniecznie (unbedingt)}

1. «bezwarunkowo, bezwzględnie, nieodwołalnie, nieodzownie»

Mówit, że Niemcy chca koniecznie wojny. GRUSZ. AN. Od Karpat 35. (Gruszecka, Aniela: Od Karpat nad Battyk. 2. Aufl. Czytelnik: Warszawa 1948.)

Solche Belegbeispiele aus Belletristik, Presse und Fachliteratur unter Lemmata, die nicht in Verbindung zum Wortfeld Gewalt stehen, offenbaren, wie sehr die traumatischen Kriegserlebnisse im polnischen Bewusstsein präsent waren.

Auch die polnische Wahrnehmung der Nachkriegssituation wird im SJPDor widergespiegelt. So kommen die Befürchtungen hinsichtlich eines erneuten Kriegsausbruchs in dem Belegbeispiel unter dem Stichwort zaburzyć (stören) zum Ausdruck, das erneut aus dem weiter oben genannten Werk des Historikers Kazimierz Piwarski stammt:

\section{zaburzyć (stören)}

Chcemy jednak wierzyć, że zwycięża czynniki, które [...] pragna takiego okietznania hydry niemieckiej, by nie byta zdolna do ponownego zaburzenia pokoju w Europie. PIW. Odra 82. (Piwarski, Kazimierz: Odra rzeka pokoju. Towarzystwo Uniwersytetu Robotniczego: Warszawa 1947. $)^{18}$

In den Belegbeispielen unter den Stichwörtern chadecja (CDU) und zrewidować (revidieren), die aus der Monatsschrift des ZK der PZPR „Nowe Drogi“ sowie einer Tageszeitung entnommen wurden, wird wiederum eine skeptische Haltung gegenüber der Politik der BRD geäußert:

\section{chadecja (Christdemokratie)}

Chadecja, stosujac kryteria wyznaniowe do spraw polityki, upodobnita się do reakcyjnego integryzmu. Nowe Drogi 3, 1963, s. 61. (Nowe Drogi. Nr. 3. Miesięcznik. Organ teoretyczny i polityczny Komitetu Centralnego Polskiej Zjednoczonej Partii Robotniczej. Warszawa 1963.) ${ }^{19}$

\section{zrewidować (revidieren)}

Domagali się aby rząd NRF zrewidowat swoja decyzję w sprawie przedawnienia zbrodni hitlerowskich. Exp. 59, 1965. (Express Wieczorny. Nr. 59. Pismo codzienne. Robotnicza Spótdzielnia Wydawnicza „Prasa“: Warszawa 1965. . $^{20}$

Weiterhin ist das Misstrauen gegenüber der BRD Inhalt eines Belegbeispiels (aus der Tageszeitung Życie Warszawy) unter dem Stichwort zimnowojenny (adjektivische Form von Kalter Krieg):

18 „Wir wollen jedoch daran glauben, dass Faktoren siegen werden, die [...] danach streben, die deutsche Hydra zu bändigen, damit sie nicht in der Lage ist, den Frieden in Europa erneut zu stören.“

19 „Die Christdemokratie begann durch Anwendung von Glaubenskriterien auf die Politik dem reaktionären Integrismus zu ähneln.“

20 „Sie forderten, die Regierung der Bundesrepublik Deutschland solle ihre Entscheidung hinsichtlich der Verjährung von NS-Verbrechen revidieren.“ 


\section{zimnowojenny (Adjektiv von Kalter Krieg)}

Została ostatnio rozpętana w Niemczech Zachodnich odwetowa, rewizjonistyczna, zimnowojenna kampania spadkobierców polityki Hitlera, wymierzona przeciw Polsce, Czechosłowacji. Życie Warsz. 213, 1960. (Życie Warszawy. Nr. 213. Pismo codzienne. Warszawa 1960.) ${ }^{21}$

Wie stark die Angst vor Revisionsforderungen war, lässt sich ebenfalls den Belegbeispielen aus der zeitgenössischen Presse unter den Stichwörtern ziomkostwo (Landsmannschaft), ziomkowski (Landsmannschafts-), zaślepieniec (Verblendeter) und czerwoność (Röte) entnehmen:

\section{ziomkostwo (Landsmannschaft)}

W różnych miastach Niemiec Zachodnich odbywaja się zjazdy tzw. ziomkostw, mające na celu podtrzymanie wśród Niemców wysiedlonych po wojnie z terenów Polski, Czechostowacji i innych krajów Środkowej Europy, duch zemsty i odwetu. Exp. 156, 1965. (Express Wieczorny. Nr. 156. Pismo codzienne. Robotnicza Spótdzielnia Wydawnicza „Prasa“: Warszawa 1965.)22

\section{ziomkowski (Landsmannschafts-)}

Rewizjonistyczne zgromadzenie ziomkowskie, które odbyło się w ostatnich dwóch dniach stycznia w Lubece otworzyło tegoroczny sezon odwetowy w NRF. Życie Lit. 12, 1965. (Życie Literackie. Nr. 12. Tygodnik. Związek Literatów Polskich: Kraków 1965.23

\section{zaślepieniec (Verblendeter)}

Któż prócz zaślepieńców może przeoczyć zagrożenie losu wielu narodów, a zwłaszcza narodu polskiego, jakie tkwi w polityce kót rządzacych w NRF. Tryb. Ludu 119, 1966. (Trybuna Ludu. Nr. 119. Pismo codzienne. Organ Komitetu Centralnego Polskiej Zjednoczonej Partii Robotniczej: Warszawa 1966. ${ }^{24}$

\section{czerwoność (Röte, Glut)}

$W$ interesie imperializmu leży zgodne z ich metodami rozpalenie do czerwoności niemieckich tendencji antypolskich $i$ odwetowych. HOROD. Pok. 12. (Horodyński, Dominik: Za pokojem - jedność narodu. Polski Komitet Obrońców Narodu: Warszawa 1950). ${ }^{25}$

In der offiziellen Propaganda der PZPR galt es, stets die Sowjetunion als Garant für die polnische Sicherheit hervorzuheben und auf das polnisch-sowjetische Bündnis zu verweisen, so wie es unter dem Lemma klin (Keil) dargestellt wird:

21 „Vor kurzem wurde in Westdeutschland im Rahmen des Kalten Krieges eine revisionistische Vergeltungskampagne von den Erben der Politik Hitlers entfacht, die gegen Polen gerichtet ist.“

22 „In verschiedenen Städten Westdeutschlands finden Kongresse sogenannter Landsmannschaften statt, die zum Ziel haben, unter den Deutschen, die nach dem Krieg aus den Gebieten Polens, der Tschechoslowakei und anderer mitteleuropäischer Länder vertrieben worden sind, den Geist der Rache und Vergeltung aufrechtzuerhalten.“

23 „Die revisionistischen Landsmannschaftsversammlungen, die in den vergangenen zwei Tagen in Lübeck stattgefunden haben, eröffneten die diesjährige Vergeltungssaison in der Bundesrepublik Deutschland.“

24 „Wer außer den Verblendeten sieht nicht die Gefährdung des Schicksals vieler Völker, und vor allem des polnischen Volkes, die von der Politik der regierenden Kreise in der Deutschen Bundesrepublik ausgeht."

25 „Im Interesse der Imperialisten liegt es, gemäß ihrer Methoden, die Glut der deutschen antipolnischen Tendenzen und Vergeltungstendenzen zu entfachen.“ 


\section{klin (Keil)}

Nie można nazywać przyjazna deklaracje, która usituje wbić klin pomiędzy Polskę a jej naturalnego sojusznika wobec groźby niemieckiej. Życie Warsz. 136, 1958. (Życie Warszawy. Nr. 136. Pismo codzienne. Warszawa 1958. $)^{26}$

Im Stichwortartikel zabezpieczenie (Absicherung) kommt erneut Kazimierz Piwarski zu Wort, der für die Oder-Neiße-Grenze als einen für den künftigen Frieden zwingend notwendigen Grenzverlauf plädiert:

\section{zabezpieczenie (Absicherung)}

Granica polska na Odrze i Nysie to niezbędne zabezpieczenie przed agresja niemiecka nie tylko naszego narodu i państwa, ale zarazem konieczna osłona całego świata stowiańskiego. PIW. Odra 136. (Piwarski, Kazimierz: Odra rzeka pokoju. Towarzystwo Uniwersytetu Robotniczego: Warszawa 1947. $)^{27}$

Wie bereits weiter oben erwähnt wurde, galt es in der Presse die offizielle Freundschaft zwischen der Volksrepublik Polen und der DDR zu betonen. Auch diese Inhalte fanden Eingang in das SJPDor. Es zeugt allerdings von einer Widerspiegelung der zeitgeschichtlichen Aspekte, dass das positive Bild der DDR lediglich in zwei Belegbeispielen innerhalb aller analysierten Stichwortartikel zum Ausdruck kommt. Die beiden einzigen Belegbeispiele mit Bezug zur DDR, die beide aus Zeitschriften stammen, finden sich unter dem Stichwort zaborczość (Machtgier):

\section{zaborczość (Machtgier)}

Demokracja niemiecka zerwała ostatecznie z wiekowa polityka zaborczości i ekspansji niemieckiej. Wiedza i Życie 1950, s. 844. (Wiedza i Życie. Miesięcznik. Organ Towarzystwa Wiedzy Powszechnej 1950.) ${ }^{28}$

und unter dem Lemma zarzewie (Brennpunkt):

\section{zarzewie (Brennpunkt)}

Nasza zachodnia granica nie jest już więcej zarzewiem wojny, lecz granica pokoju. Skrzydła 28, 1950. (Skrzydła i Motor. Nr. 28. Tygodnik młodzieży lotniczej. Liga Lotnicza: Warszawa 1950. $)^{29}$

Die Unterscheidung zwischen BRD und DDR kommt im SJPDor hingegen kaum zum Ausdruck. Dies äußert sich z.B. darin, dass ein Stichwort wie wschodnioniemiecki (ostdeutsch) nicht im SJPDor verzeichnet ist, wohingegen das Lemma zachodnioniemiecki (westdeutsch) aufgenommen wurde. Auch dieses Stich-

${ }^{26}$ „Eine solche Erklärung, die versucht einen Keil zu treiben zwischen Polen und seinen natürlichen Verbündeten gegen die deutsche Bedrohung, lässt sich nicht als freundschaftlich bezeichnen."

27 „Die Grenze Polens an Oder und Neiße ist eine unumgängliche Absicherung nicht nur unseres Volkes und Staates, sondern der gesamten slawischen Welt vor der deutschen Aggression.“

28 „Die deutsche Demokratie brach letztendlich mit der jahrhundertealten deutschen Politik der Raffgier und Expansion.“

29 „Unsere westliche Grenze ist kein Brennpunkt des Krieges mehr, sondern eine Grenze des Friedens.“ 
wort wurde anhand eines Belegbeispiels (aus der Tageszeitung Życie Warszawy) veranschaulicht, in dem vor der fortbestehenden Gefahr durch den westdeutschen Militarismus gewarnt wird:

\section{zachodnioniemiecki (westdeutsch)}

Niebezpieczeństwo zagrażajace pokojowi ze strony militaryzmu zachodnioniemieckiego pozostaje wcią̇ aktualne. Życie Warsz. 85, 1965. (Życie Warszawy. Nr. 85. Pismo codzienne. Warszawa 1965. $)^{30}$

\section{Fazit}

Die Analyse der Lemmastrecken A, B, C, Ć, K, Z, Ź und Ż im SJPDor ergibt, dass in den Belegbeispielen innerhalb von 162 Stichwortartikeln auf die Geschichte der deutsch-polnischen Beziehungen vom Mittelalter bis in die 60er Jahre des 20. Jahrhunderts Bezug genommen wird. Berücksichtigt man die Gesamtanzahl von 30580 untersuchten Stichwortartikeln, erscheint die Zahl der Stichwortartikel, in denen das deutsch-polnische Verhältnis Erwähnung findet, natürlich sehr gering, sie macht nur $0,5 \%$ aus. Ausschlaggebend ist jedoch nicht die Quantität, sondern die Tatsache, welche Inhalte die entsprechenden Belegbeispiele transportieren, in welchen Wortfeldern sie vertreten sind und welches Deutschenbild sie vermitteln. So ist die hohe Anzahl von Belegbeispielen mit Deutschenbezug unter Stichwortartikeln aus den Wortfeldern „Krieg“ und „Gewalt", aber auch unter negativ konnotierten Lemmata auffällig. Dabei bezieht sich fast die Hälfte aller Belegbeispiele, in denen die Deutschen thematisiert werden, auf die Kriegserfahrungen. Beispielsätze dieser Art sind ebenfalls unter nicht negativ konnotierten Stichwörtern zu finden. Aber auch das bereits vor dem Zweiten Weltkrieg existente polnische Deutschenbild floss in das SJPDor mit Belegbeispielen aus der Literatur des 19. Jahrhunderts ein.

Insgesamt vermitteln die Belegbeispiele in den oben genannten 162 Stichwortartikeln ein fast ausnahmslos negatives Deutschenbild. Die wenigen Ausnahmen bilden die beiden zuvor genannten Belegbeispiele unter den Lemmata zaborczość (Machtgier) und zarzewie (Brennpunkt), in denen ein positives Bild der DDR vermittelt wird, zwei Beispielsätze unter den Stichwörtern kieresz (in der Bedeutung «zadawanie ran, kiereszowanie» - Verprügeln, Verletzen) ${ }^{31}$ und którykolwiek (welcher auch immer), ${ }^{32}$ in denen Deutsche in einem neutralen

30 „Die Gefahr für den Frieden von Seiten des westdeutschen Militarismus bleibt nach wie vor aktuell."

${ }^{31}$ Ha! hultaje! - krzyknie pan przez okno - to znowu Niemców kiereszujecie! Poczekajcie, dam ja wam tu kieresze! KACZK. Mąż 89. (Kaczkowski, Zygmunt: „Mąż szalony“. In: Wybór pism. Bd. 1. Gebethner i Wolff: Warszawa 1900, S. 1-260) (,,Ha, ihr Halunken!' ruft der Herr aus dem Fenster. ,Ihr prügelt also wieder die Deutschen! Wartet, gleich könnt ihr was erleben!").

${ }^{32}$ Którykolwiek z Niemców bliżej pod mury podstępowali, bito ich kamieniami. OLESZ. Wspom. 27. (Oleszyński, Antoni: Wspomnienia o Polakach, co stynęli w obcych i odległych krajach. 
Kontext auftauchen, sowie ein Satz unter dem Lemma czterdziestolecie ${ }^{33}$ (Phase von 40 Jahren), der sich auf einen friedlichen Zeitraum in der frühen Phase der deutsch-polnischen Nachbarschaft bezieht.

Darüber hinaus gibt es in den untersuchten Lemmastrecken nur ein Belegbeispiel (unter dem Stichwort berliniarz), in dem Deutsche mit positiven Eigenschaften beschrieben werden:

\section{berliniarz (od berlinkarz - Besitzer eines Flussschiffes, Schiffer)}

W odległości blisko wiorstowej stamtąd znajdował się most, przy moście przystań berlinek, [...] berliniarze, zręczni, inteligentni Niemcy, od razu rzecz zrozumieli. GOMUL. Wspom. 142. (Gomulicki, Wiktor: Wspomnienia niebieskiego mundurka. 12. Aufl. Gebethner i Wolff: Warszawa 1949.)

(,,Fast einen Werst davon entfernt befand sich eine Brücke und an der Brücke eine Anlegestelle für Flussschiffe; [...] die Schiffer, geschickte intelligente Deutsche, verstanden sofort, um was es ging. ")

Es bleibt zu untersuchen, ob und wenn ja, welches Deutschenbild man in modernen polnischen Sprachwörterbüchern antreffen würde.

\section{Literatur}

\section{Quellen}

Doroszewski, Witold (Hrsg.) (1958-1969): Słownik języka polskiego. 11 Bde. Warszawa.

\section{Sekundärliteratur}

Bartnicka, Barbara (2000): Udział słownictwa XIX-wiecznego w Słowniku języka polskiego pod redakcja Witolda Doroszewskiego. In: Poradnik Językowy. Nr 1. S. 18-23.

Dąbrowska, Maria (2009): Dzienniki 1914-1965. Bd. 7. 1950. Warszawa.

Kiwerska, Jadwiga (1993): W atmosferze wrogości (1945-1970). In: Wolff-Powęska, A. (Hrsg.): Polacy wobec Niemców. Z dziejów kultury politycznej Polski 1945-1989. Poznań. S. 45-93.

Piwarski, Kazimierz (1947): Odra rzeka pokoju. Warszawa.

Sakson, Andrzej (1993): Niemcy w świadomości społecznej Polaków. In: Wolff-Powęska, A. (Hrsg.): Polacy wobec Niemców. Poznań. S. 408-430.

Opisy $i$ wizerunki. Teil 1. Drukarnia Maulde i Renon: Paris 1843.) (,,Wer auch immer von den Deutschen an die Mauern herantrat, wurde mit Steinen angegriffen.")

33 czterdziestolecie (Bedeutung 1. «okres czterdziestu lat»-Phase von 40 Jahren)

W ciagu pierwszego czterdziestolecia istnienia państwa piastowskiego stosunki między Polska a Niemcami wykazuja fazy pokoju i przymierza. LAB. Studia 345. (Labuda, Gerard: Studia nad początkami Państwa Polskiego. Księgarnia Akademicka: Poznań 1946.)

(,, Während der ersten 40 Jahre des Piastenstaates weisen die deutsch-polnischen Beziehungen Phasen des Friedens und der Bündnisse auf.") 
Wrzesiński, Wojciech (1994): Nachbar oder Feind. Das Klischee des Deutschen in Polen im 19. und 20. Jahrhundert. In: Grucza, Franciszek (Hrsg.): Vorurteile zwischen Deutschen und Polen: Materialien des deutsch-polnischen wissenschaftlichen Symposiums 9. bis 11. Dezember 1992, Görlitz-Zgorzelec. Warszawa. S. 63-75.

Zernack, Klaus (2001): Deutsch-polnische Beziehungen im historischen Überblick. In: Grucza, F. (Hrsg.): Tausend Jahre polnisch-deutsche Beziehungen. Sprache - Literatur-Kultur-Politik. Materialien des Millenium-Kongresses 5.-8. April 2000, Warszawa. Warszawa. S. 88-106. 